\title{
Chasing a rarity: a retrospective single-center evaluation of prognostic factors in primary gliosarcoma
}

\author{
Cas S. Dejonckheere' $\cdot$ Alexander M. C. Böhner ${ }^{1,2}$ - David Koch ${ }^{1}$ Leonard C. Schmeel Ulrich Herrlinger $^{3}$.

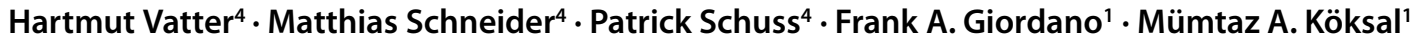

Received: 6 June 2021 / Accepted: 21 November 2021 / Published online: 22 December 2021

(c) The Author(s) 2021

\begin{abstract}
Background and purpose Primary gliosarcoma (GS) is a rare variant of $I D H$-wildtype glioblastoma multiforme. We performed a single-center analysis to identify prognostic factors.

Patients and methods We analyzed the records of 26 patients newly diagnosed with primary WHO grade IV GS. Factors of interest were clinical and treatment data, as well as molecular markers, time to recurrence, and time to death.

Results Median follow-up was 9 months (range 5-21 months). Gross total resection did not lead to improved survival, most likely due to the relatively small sample size. Low symptom burden at the time of diagnosis was associated with longer PFS $(P=0.023)$ and OS $(P=0.018)$. Median OS in the entire cohort was 12 months. Neither MGMT promoter hypermethylation nor adjuvant temozolomide therapy influenced survival, consistent with some previous reports.

Conclusion In this retrospective study, patients exhibiting low symptom burden at diagnosis showed improved survival. None of the other factors analyzed were associated with an altered outcome.
\end{abstract}

Keywords Gliosarcoma · Glioblastoma multiforme · Brain tumor · IDH-wildtype · MGMT promoter · Radiotherapy · Temozolomide

\section{Highlights}

- Data on prognosis and prognostic factors in gliosarcoma are scarce.

- The median OS in this single-center study was 12 months.

- Patients exhibiting low symptom burden at diagnosis showed improved survival.

- Neither MGMT promoter hypermethylation nor adjuvant treatment with temozolomide had an impact on survival.

The authors Cas S. Dejonckheere and Alexander M.C. Böhner contributed equally to the manuscript.

Mümtaz A. Köksal

muemtaz.koeksal@ukbonn.de

1 Department of Radiation Oncology, University Hospital Bonn, Venusberg-Campus 1, 53127 Bonn, Germany

2 Institutes for Molecular Medicine and Experimental Immunology, University Hospital Bonn, Bonn, Germany

3 Division of Clinical Neuro-Oncology, Department of Neurology, University Hospital Bonn, Bonn, Germany

4 Department of Neurosurgery, University Hospital Bonn, Bonn, Germany

\section{Introduction}

Gliosarcoma (GS) is a rare variant of glioblastoma multiforme (GBM), accounting for about $2 \%$ of cases [1-3]. It can be divided into primary (de novo) and secondary (after prior GBM treated with radiation) GS [4, 5]. It is typically diagnosed in the fifth or sixth decade and is about twice as common in men $[2,5,6]$. GS is usually located in the supratentorial region, with a predilection for the temporal lobe $[5,7,8]$. Presenting symptoms include signs of raised intracranial pressure (e.g., headaches, nausea, and vomiting), visual disturbances, or seizures [5, 9]. Histopathologically, it is characterized by a biphasic growth pattern, including both a glial and an atypical sarcomatous component, descending from a monoclonal origin [10]. In the latest WHO classification, it is regarded as a subtype of the isocitrate dehydrogenase $(I D H)$ wildtype GBM, although $I D H$-mutated GS has been described $[1,11]$.

Because of its only sporadic occurrence, GS is treated in a similar manner to classical GBM, with a multimodal therapeutic approach including maximal safe surgical resection, external beam radiotherapy, and temozolomide-based chemotherapy [12-14]. A historic cohort showed a median 


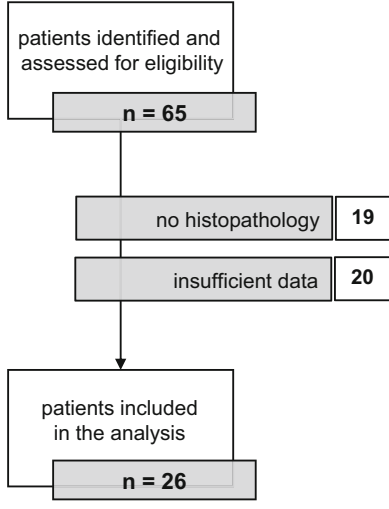

Fig. 1 Flowchart of patient selection

overall survival (OS) of only 4 months if left untreated [15]. With treatment, GS continues to have a poor prognosis, with a median OS around 15 months comparable to that of GBM, thus making it one of the tumors of the central nervous system with the lowest relative survival rate $[1,7$, 16-18].

In the current study, we present a cohort of 26 GS patients treated at a single center, reviewing their demographic, clinical, and treatment characteristics (16 distinct factors in total). Conclusively, we aim to identify possible independent factors that might be related to an improved outcome.

\section{Patients and methods}

\section{Patients}

An overview of patient selection is presented in Fig. 1. Using structured query language (SQL), the clinical database was searched for cases of GS between January 1995 and May 2021. All matching patient records were analyzed and cases with available information and histopathologically confirmed (by reference neuropathology) GS were included. The following data were extracted: age at diagnosis, gender, tumor location, MGMT promotor methylation status and IDH mutational status (where available), presenting symptoms and duration, size, surgical treatment (including extent of resection), first-line radiotherapy, firstline chemotherapy, complications, time to recurrence, and time to death. This study was approved by the local ethics committee.

\section{Treatment and follow-up}

Patients were treated per institutional standards, following interdisciplinary case discussion. In the majority of cases, the postoperative Stupp regimen was indicated, consisting of fractionated focal irradiation in daily fractions of $2 \mathrm{~Gy}$ given 5 days per week for 6 weeks for a total of $60 \mathrm{~Gy}$, with continuous daily temozolomide during radiation treatment, followed by up to six cycles of adjuvant temozolomide [12]. Older or unfit patients received a reduced radiation dose, with 2.67 Gy 5 days per week for 3 weeks, for a total of $40.05 \mathrm{~Gy}$.

Therapy was monitored weekly during treatment. Upon completion, patients underwent regular assessment of their neurologic status. The first follow-up imaging was scheduled at 6 weeks after completion of the radiation course, then every 3 months, or sooner if indicated.

\section{Statistical analysis}

To identify dependencies of factors on characteristics specific to GS patient data (such as tumor size), linear regressions between pairs of parameters were calculated. Goodness of fit of the regression was provided as $\mathrm{R}^{2}$. Statistical dependency of a pair of parameters was assumed if the slope deviance from zero of the regression yielded a $P<0.05$. For all other relevant factors, a multivariate survival analysis (Cox regression) was performed. For the comparison of outcomes (i.e., survival) by patient group presorted, e.g., by their MGMT promotor methylation status or IDH mutational status, the Kaplan-Meier survival estimate was used together with the logrank test to generate $P$-values. Patients were censored at the time of death or last follow-up. The statistical analysis was carried out using GraphPad Prism (GraphPad Software v.9.1.0, San Diego, CA 92108, USA).

\section{Literature search and external data obtainment}

A literature search was conducted to identify other original cohorts. The following inclusion criteria were applied: published after 2000, at least 20 patients included, and median OS reported. Excluded were cohorts with exclusively secondary GS, review articles with pooled analyses (to eliminate double inclusions), and registry studies (with high patient counts, for demonstrative purposes).

\section{Results}

\section{Follow-up and patient characteristics}

A total of 26 GS patients were identified, all primary, with a median age of 61 years (range $38-84$ years; Table 1 ). The median follow-up for the entire cohort was 9 months (range 5-21 months). Seventeen patients (65.4\%) were male (male to female ratio 1.9:1). All GS manifestations were located in the supratentorial region, with a preference for the temporal lobe (10 patients, $38.5 \%$ ). The median maximum diameter at diagnosis was $4.1 \mathrm{~cm}$ (range $1.0-8.0 \mathrm{~cm}$ ). All patients 
Table 1 Summary of patient and tumor characteristics $(n=26)$

\begin{tabular}{|c|c|}
\hline Characteristic & $n(\%)$ \\
\hline Median age (range) in years & $61(38-84)$ \\
\hline \multicolumn{2}{|l|}{ Gender } \\
\hline Male & $17(65.4)$ \\
\hline Female & $9(34.6)$ \\
\hline \multicolumn{2}{|l|}{ Location } \\
\hline Right & $16(61.5)$ \\
\hline Left & $10(38.5)$ \\
\hline Temporal & $10(38.5)$ \\
\hline Frontal & $4(15.4)$ \\
\hline Occipital & $4(15.4)$ \\
\hline Parietal & $3(11.5)$ \\
\hline Multiple lobes & $5(19.2)$ \\
\hline \multicolumn{2}{|l|}{ MGMT promotor status } \\
\hline Unmethylated & $12(63.2)$ \\
\hline Hypermethylated & $7(36.8)$ \\
\hline Unknown & $7(26.9)$ \\
\hline \multicolumn{2}{|l|}{ IDH status } \\
\hline Wildtype & $16(100.0)$ \\
\hline Mutated & $0(0.0)$ \\
\hline Unknown & $10(38.5)$ \\
\hline \multicolumn{2}{|l|}{ KPS at diagnosis } \\
\hline 100 & $6(23.1)$ \\
\hline 90 & $8(30.8)$ \\
\hline 80 & $6(23.1)$ \\
\hline$\leq 70$ & $6(23.1)$ \\
\hline \multicolumn{2}{|l|}{ Duration of symptoms } \\
\hline Acute event & $5(19.2)$ \\
\hline Days & $6(23.1)$ \\
\hline Weeks & $10(38.5)$ \\
\hline Months & $5(19.2)$ \\
\hline \multicolumn{2}{|l|}{ Presenting symptoms } \\
\hline Single & $6(23.1)$ \\
\hline Multiple & $20(76.9)$ \\
\hline Headache & $11(42.3)$ \\
\hline Visual disturbances & $8(30.8)$ \\
\hline Seizure & 7 (26.9) \\
\hline Motor dysfunction & $6(23.1)$ \\
\hline Vertigo & $5(19.2)$ \\
\hline Cognitive deficit & $5(19.2)$ \\
\hline Speech dysfunction & $4(15.4)$ \\
\hline Sensory dysfunction & $3(11.5)$ \\
\hline Ataxia & $3(11.5)$ \\
\hline Mood disorder & $3(11.5)$ \\
\hline Isolated cranial nerve dysfunction & $2(7.7)$ \\
\hline Coma & $1(3.8)$ \\
\hline Other $^{\mathrm{a}}$ & $3(11.5)$ \\
\hline $\begin{array}{l}\text { Median maximum diameter at diagnosis (range) } \\
\text { in } \mathrm{cm}^{b}\end{array}$ & $4.1(1.0-8.0)$ \\
\hline
\end{tabular}

Table 1 (Continued)

\begin{tabular}{ll}
\hline Characteristic & $n(\%)$ \\
\hline Surgery & $26(100.0)$ \\
Gross total resection & $18(75.0)$ \\
Near total resection & $2(8.3)$ \\
Subtotal resection & $4(16.7)$ \\
Unknown & $2(7.7)$ \\
Radiotherapy (first line) & $26(100.0)$ \\
$30 \times 2$ Gy & $18(69.2)$ \\
Chemotherapy (first line) & $20(76.9)$ \\
Temozolomide & $19(73.1)$ \\
CCNU & $4(15.4)$ \\
Median progression free survival (range) in & $7(0-20)$ \\
months & $12(3-21)$ \\
Median overall survival (range) in months &
\end{tabular}

$M G M T$ O-6-methylguanine-DNA methyltransferase, $I D H$ isocitrate dehydrogenase, KPS Karnofsky performance status, $C C N U$ lomustine ${ }^{a}$ Other symptoms include hiccup, emesis, and urinary incontinence

${ }^{\mathrm{b}}$ In 1 patient, tumor diameter was unknown

${ }^{\mathrm{c}} \mathrm{CCNU}$ was always given in combination with temozolomide

underwent surgery followed by radiation treatment. Gross total resection (GTR) was achieved in 18 patients $(75.0 \%)$. Nineteen patients $(73.1 \%)$ received temozolomide. Molecular genetics revealed $M G M T$ promotor hypermethylation in 7 cases $(36.8 \%)$. All tumors were $I D H I$ wildtype.

\section{Symptom load}

Headache was the most common presenting symptom, occurring in 11 patients $(42.3 \%)$, followed by visual disturbances ( 8 patients, 30.8\%) and seizures (7 patients, 26.9\%). One patient was diagnosed during pregnancy. Extracranial manifestation was not seen, although 1 patient presented with meningeal spread upon recurrence.

\section{Outcome}

At the time of analysis, 6 patients (23.1\%) were still alive, and 3 of them (11.5\%) had not reached progression. The median progression-free survival (PFS) in this cohort was 7 months (range 0-20 months), with a median OS of 12 months (range from 3-21 months). One patient died during radiation treatment, from an unrelated cause (endocarditis).

In the statistical analysis (Fig. 2), patients presenting with a single symptom upon diagnosis had better PFS $(P=0.023$; Fig. 2a) and OS $(P=0.018$; Fig. $2 b)$. Patients with a smaller tumor were, unsurprisingly, more likely to achieve gross total resection (GTR; $P=0.0076$; Fig. 2c).

Other variables including age at diagnosis, gender, $M G M T$ promotor methylation status (Fig. 2d,e), preoperative performance status, tumor size, extent of resection, 
a

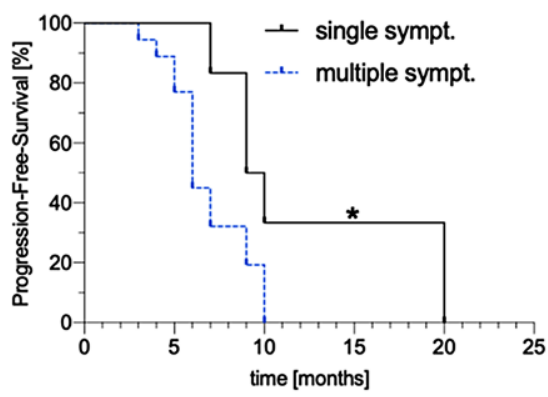

d

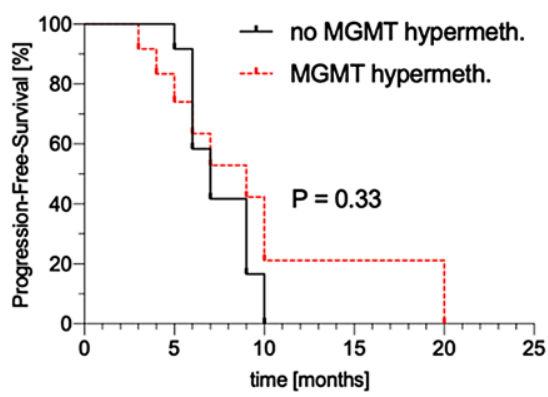

b

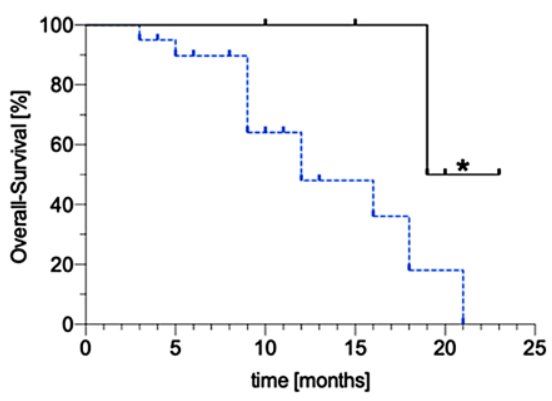

e

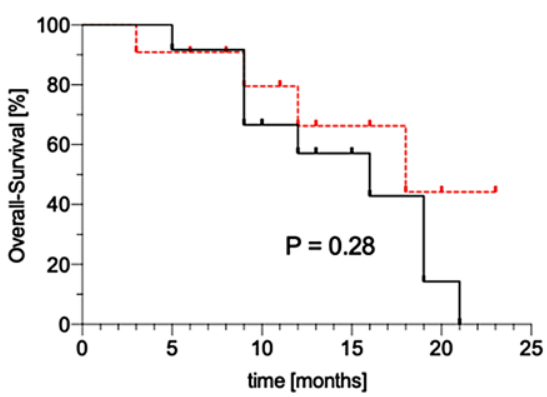

c

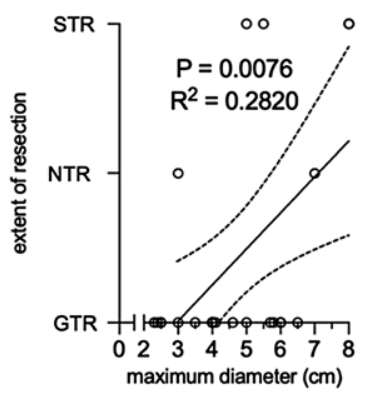

f

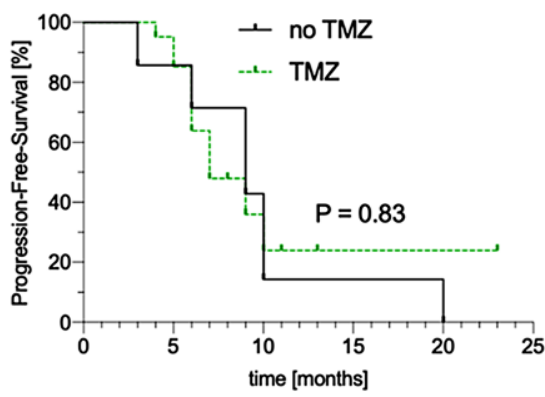

Fig. 2 Statistical analysis of the gliosarcoma patient cohort. a Dependency of PFS on symptom load $(P=0.023)$. b Dependency of OS on symptom load $(P=0.018)$. c Correlation between extent of resection and maximum tumor diameter $(P=0.0076)$. d Dependency of PFS on $M G M T$ promoter methylation status $(P=0.33)$. e Dependency of OS on MGMT promoter methylation status $(P=0.28)$. $\mathbf{f}$ Dependency of PFS on TMZ therapy $(P=0.83)$. Significance level asterisk for $P<0.05$. PFS progression free survival, $O S$ overall survival, GTR gross total resection, NTR near total resection, $S T R$ subtotal resection, $M G M T$ O-6-methylguanine-DNA methyltransferase, $T M Z$ temozolomide

and temozolomide-based chemotherapy (Fig. 2f) were not associated with survival.

\section{Review of literature}

In the literature search, 17 similar original cohorts were identified, accounting for a total of 647 included GS patients [4-6, 8, 13, 17-31]. A comparison of the median OS is displayed in Fig. 3. There seems to be wide variation in the observed median OS between published GS cohorts (range 5.7-18.5 months).

\section{Discussion}

In this retrospective analysis, we present a cohort of 26 GS cases treated at a single center. The demographic and clinical characteristics of our cohort are comparable to previously conducted research [2, 5-7, 9].

Patients presenting with a single symptom upon diagnosis showed improved survival. In 3 of these 6 cases, the symptom was a new-onset seizure in an otherwise healthy individual, warranting prompt investigation, and thus quickly leading to diagnosis and treatment of an intracranial tumor in an early stage. These patients also generally showed a higher Karnofsky performance status.
The extent of tumor resection is a well-established independent prognostic factor for improved OS in GBM [19]. It has also been described in GS [2, 18, 20, 21, 32]. In the current study, GTR did not lead to improved survival. We reason that this might be attributed to the small sample size, since all studies reporting a significant influence on survival had larger patient numbers.

Whether MGMT promotor methylation status influences survival in GS remains a matter of ongoing debate. Hypermethylation leads to epigenetic silencing of the $M G M T$ gene. Its product, a DNA repair enzyme, restores alkylating agent-induced damage [22]. Hypermethylation of the $M G M T$ promotor thus reflects the efficacy of alkylating agents such as temozolomide, and has been thoroughly associated with improved outcome in GBM patients [19]. Reports on the prevalence of MGMT promotor hypermethylation and its association with survival in GS are conflicting, however. Some authors reported less frequent hypermethylation in comparison to GBM and used this as an explanation for their observed worse prognosis in GS [7, 23, 32]. In contrast, others suggested more hypermethylation in GS [21, 22]. In the current study, MGMT promotor methylation status did not influence survival, consistent with some previous reports $[9,24]$. The largest GS registry study to date (with 1102 included patients) found no apparent dif- 
a

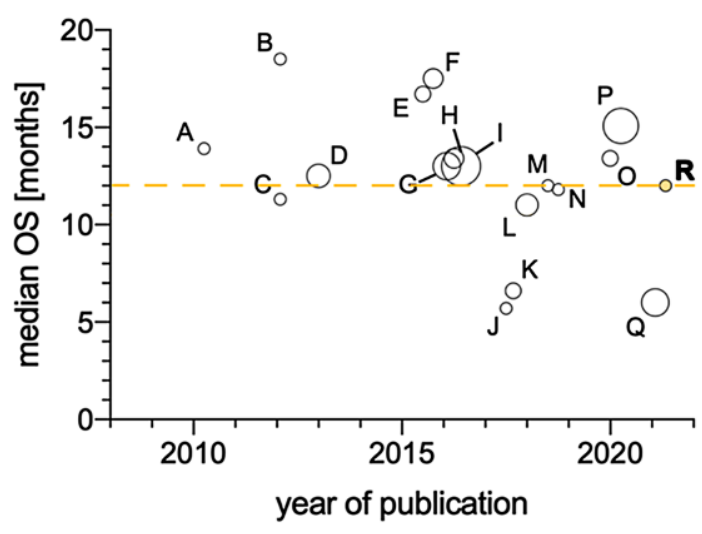

b

\begin{tabular}{|r|c|c|c|c|c|}
\hline & author & date & med PFS [months] & med OS [months] & n (patients) \\
\hline A & Han & 2010 & 3 & 13.9 & 20 \\
\hline B & Singh & 2012 & $?$ & 18.5 & 22 \\
\hline C & Lee & 2012 & $?$ & 11.3 & 26 \\
\hline D & Walker & 2013 & $?$ & 12.5 & 46 \\
\hline E & Rath & 2015 & 15 & 16.7 & 27 \\
\hline F & Cachia & 2015 & 6.4 & 17.5 & 34 \\
\hline G & Zhang & 2016 & 8 & 13 & 51 \\
\hline H & Adeberg & 2016 & 7.8 & 13.4 & 37 \\
\hline I & Castelli & 2016 & 7 & 13 & 75 \\
\hline J & Jain & 2017 & 5 & 5.7 & 21 \\
\hline K & Ma & 2017 & $?$ & 6.6 & 33 \\
\hline L & Smith & 2017 & 5.6 & 11 & 22 \\
\hline M & Yi & 2018 & $?$ & 12 & 48 \\
\hline N & Peckham & 2018 & $?$ & 11.8 & 25 \\
\hline O & Frandsen & 2019 & 6.8 & 13.4 & 33 \\
\hline P & Jin & 2020 & 5.55 & 15.07 & 71 \\
\hline Q & Pierscianek & 2021 & $?$ & 6 & 56 \\
\hline R & Dejonckheere \& Böhner & 2021 & 7 & 12 & 26 \\
\hline
\end{tabular}

Fig. 3 a Comparison of median OS in gliosarcoma cohorts published after 2000 with at least 20 patients [4-6, 8, 13, 17-30]. Bubble size indicates patient count. b There is wide variation in the observed median OS (range 5.7-18.5 months). The present study is highlighted in yellow (12 months). The weighted median OS across all studies was 12.9 months. OS overall survival, $P F S$ progression-free survival

ference in $M G M T$ promotor hypermethylation between GS and GBM, nor did it influence survival in GS patients [18].

Adjuvant temozolomide therapy has become the standard of care in GBM management, leading to a statistically significant and clinically relevant survival benefit [12]. This has also been reported to some degree in GS, albeit mostly in studies with small patient numbers [6, 20, 33, 34]. The largest registry study so far, however, confirmed the superiority of trimodality therapy also in GS [18]. In the current study, there was no statistically significant difference in survival among patients receiving adjuvant temozolomide therapy.

A multitude of other favorable prognostic factors has been reported in the literature, including younger age at diagnosis [2, 18, 23, 25-27, 35], female sex [18], temporal tumor location [7], preoperative performance status [23, 25], and tumor size [23, 26]. These are, however, often not replicated because of small patient numbers, and were also not observed in the present cohort.

The median OS in this cohort was 12 months. There is wide variation in reported median OS in the available literature (Fig. 3; range 5.7-18.5 months). The largest conducted registry study on GS reported a median OS of 10.7 months, comparable to the current cohort [18].

Our study harbors several limitations, most importantly its retrospective nature and relatively small sample size. Furthermore, we did not compare our data to a control group of GBM patients. In earlier cases, information on survival was often missing, which could have been a potential source of bias. However, because of the rarity of GS, we reason that an accurate depiction of GS patients treated at our center is of value and adds to the existing data on GS management.

With a 5-year OS rate of only $5.6 \%$, GS remains a rare tumor entity with a dismal prognosis [17]. Although overlap with GBM exists, GS appears to be a separate tumor entity, with variation in reported prognostic factors. Prospective studies with data on molecular pathology are needed to unequivocally establish such patient and tumor characteristics, aiding patient management and improving care for all GS patients. National and international collaborations could serve useful herein, to facilitate patient recruitment. Until then, a multimodality approach, with surgery aiming for complete resection followed by radiation and chemotherapy, seems to be the most favorable option.

Funding Open Access funding enabled and organized by Projekt DEAL.

Conflict of interest C.S. Dejonckheere, A.M.C. Böhner, D. Koch, L.C. Schmeel, U. Herrlinger, H. Vatter, M. Schneider, P. Schuss, F.A. Giordano, and M.A. Köksal declare that they have no competing interests.

Open Access This article is licensed under a Creative Commons Attribution 4.0 International License, which permits use, sharing, adaptation, distribution and reproduction in any medium or format, as long as you give appropriate credit to the original author(s) and the source, provide a link to the Creative Commons licence, and indicate if changes were made. The images or other third party material in this article are included in the article's Creative Commons licence, unless indicated otherwise in a credit line to the material. If material is not included in the article's Creative Commons licence and your intended use is not permitted by statutory regulation or exceeds the permitted use, you will need to obtain permission directly from the copyright holder. To view a copy of this licence, visit http://creativecommons.org/licenses/by/4. $0 /$.

\section{References}

1. Louis DN, Perry A, Reifenberger G, von Deimling A, FigarellaBranger D, Cavenee WK et al (2016) The 2016 world health organization classification of tumors of the central nervous system: a summary. Acta Neuropathol 131:803-820. https://doi.org/10. 1007/s00401-016-1545-1 
2. Kozak KR, Mahadevan A, Moody JS (2009) Adult gliosarcoma: epidemiology, natural history, and factors associated with outcome. Neuro Oncol 11:183-191. https://doi.org/10.1215/15228517-2008076

3. Heesters M, Molenaar W, Go GK (2003) Radiotherapy in supratentorial gliomas. A study of 821 cases. Strahlenther Onkol 179:606-614. https://doi.org/10.1007/s00066-003-1098-9

4. McAleer MF, Brown PD (2015) Therapeutic management of gliosarcoma in the temozolomide era. CNS Oncol 4:171-178. https://doi.org/10.2217/cns.14.61

5. Cachia D, Kamiya-Matsuoka C, Mandel JJ, Olar A, Cykowski MD, Armstrong TS et al (2015) Primary and secondary gliosarcomas: clinical, molecular and survival characteristics. J Neurooncol 125:401-410. https://doi.org/10.1007/s11060-015-1930-y

6. Smith DR, Wu C-C, Saadatmand HJ, Isaacson SR, Cheng SK, Sisti MB et al (2018) Clinical and molecular characteristics of gliosarcoma and modern prognostic significance relative to conventional glioblastoma. J Neurooncol 137:303-311. https://doi.org/ 10.1007/s11060-017-2718-z

7. Frandsen S, Broholm H, Larsen VA, Grunnet K, Møller S, Poulsen HS et al (2019) Clinical characteristics of gliosarcoma and outcomes from standardized treatment relative to conventional glioblastoma. Front Oncol 9:1425. https://doi.org/10.3389/fonc. 2019.01425

8. Moon SK, Kim EJ, Choi WS, Ryu CW, Park BJ, Lee J (2010) Gliosarcoma of the cerebellar hemisphere: a case report and review of the literature. Korean J Radiol 11:566-570. https://doi.org/10. 3348/kjr.2010.11.5.566

9. Singh G, Mallick S, Sharma V, Joshi N, Purkait S, Jha P et al (2012) A study of clinico-pathological parameters and $\mathrm{O}^{6}$-methylguanine DNA methyltransferase (MGMT) promoter methylation status in the prognostication of gliosarcoma. Neuropathology 32:534-542. https://doi.org/10.1111/j.1440-1789.2012.01297.x

10. Feigin IH, Gross SW (1955) Sarcoma arising in glioblastoma of the brain. Am J Pathol 31:633-653

11. de Macedo Filho LJM, Barreto EG, Martins PLB, Filho ENS, Gerson G, de Albuquerque LAF (2020) IDH1-mutant primary intraventricular gliosarcoma: case report and systematic review of a rare location and molecular profile. Surg Neurol Int 11:372. https://doi. org/10.25259/SNI_586_2020

12. Stupp R, Mason WP, van den Bent MJ, Weller M, Fisher B, Taphoorn MJB et al (2005) Radiotherapy plus concomitant and adjuvant temozolomide for glioblastoma. N Engl J Med 352:987-996. https://doi.org/10.1056/NEJMoa043330

13. Combs SE, Gutwein S, Schulz-Ertner D, van Kampen M, Thilmann C, Edler L et al (2005) Temozolomide combined with irradiation as postoperative treatment of primary glioblastoma multiforme. Phase I/II study. Strahlenther Onkol 181:372-377. https:// doi.org/10.1007/s00066-005-1359-x

14. Seidel C, von Bueren AO, Bojko S, Hoffmann M, Pietsch T, Gielen GH et al (2018) Concurrent radiotherapy with temozolomide vs. concurrent radiotherapy with a cisplatinum-based polychemotherapy regimen: acute toxicity in pediatric high-grade glioma patients. Strahlenther Onkol 194:215-224. https://doi.org/10.1007/s00066017-1218-6

15. Morantz RA, Feigin I, Ransohoff J 3rd (1976) Clinical and pathological study of 24 cases of gliosarcoma. J Neurosurg 45:398-408. https://doi.org/10.3171/jns.1976.45.4.0398

16. Han SJ, Yang I, Tihan T, Prados MD, Parsa AT (2010) Primary gliosarcoma: key clinical and pathologic distinctions from glioblastoma with implications as a unique oncologic entity. J Neurooncol 96:313-320. https://doi.org/10.1007/s11060-009-9973-6

17. Truitt G, Gittleman H, Leece R, Ostrom QT, Kruchko C, Armstrong TS et al (2019) Partnership for defining the impact of 12 selected rare CNS tumors: a report from the CBTRUS and the NCI-
CONNECT. J Neurooncol 144:53-63. https://doi.org/10.1007/ s11060-019-03215-x

18. Frandsen J, Orton A, Jensen R, Colman H, Cohen AL, Tward J et al (2018) Patterns of care and outcomes in gliosarcoma: an analysis of the national cancer database. J Neurosurg 128:1133-1138. https:// doi.org/10.3171/2016.12.JNS162291

19. Gittleman H, Lim D, Kattan MW, Chakravarti A, Gilbert MR, Lassman $\mathrm{AB}$ et al (2017) An independently validated nomogram for individualized estimation of survival among patients with newly diagnosed glioblastoma: NRG oncology RTOG 0525 and 0825 . Neuro Oncol 19:669-677. https://doi.org/10.1093/neuonc/now208

20. Jin MC, Liu EK, Shi S, Gibbs IC, Thomas R, Recht L et al (2020) Evaluating surgical resection extent and adjuvant therapy in the management of gliosarcoma. Front Oncol 10:337. https://doi.org/ 10.3389/fonc. 2020.00337

21. Zhang G, Huang S, Zhang J, Wu Z, Lin S, Wang Y (2016) Clinical outcome of gliosarcoma compared with glioblastoma multiforme: a clinical study in Chinese patients. J Neurooncol 127:355-362. https://doi.org/10.1007/s11060-015-2046-0

22. Kang S-H, Park K-J, Kim C-Y, Yu MO, Park C-K, Park S-H et al (2011) O6-methylguanine DNA methyltransferase status determined by promoter methylation and immunohistochemistry in gliosarcoma and their clinical implications. J Neurooncol 101:477-486. https://doi.org/10.1007/s11060-010-0267-9

23. Pierscianek D, Ahmadipour Y, Michel A, Rauschenbach L, Darkwah Oppong M, Deuschl C et al (2021) Demographic, radiographic, molecular and clinical characteristics of primary gliosarcoma and differences to glioblastoma. Clin Neurol Neurosurg 200:106348. https://doi.org/10.1016/j.clineuro.2020.106348

24. Jain A, Correia J, Schweder P, McMahon A, Merola J, Aspoas R (2017) Analysis of outcomes of multidisciplinary management of gliosarcoma: a single-center study, 2000-2013. World Neurosurg 106:30-36. https://doi.org/10.1016/j.wneu.2017.06.073

25. Ahmed FI, Abdullah KG, Durgin J, Salinas RD, O'Rourke DM, Brem S (2019) Evaluating the association between the extent of resection and survival in gliosarcoma. Cureus 11:e4374. https://doi. org/10.7759/cureus.4374

26. Feng S-S, Li H-B, Fan F, Li J, Cao H, Xia Z-W et al (2019) Clinical characteristics and disease-specific prognostic nomogram for primary gliosarcoma: a SEER population-based analysis. Sci Rep 9:10744. https://doi.org/10.1038/s41598-019-47211-7

27. Huang Q, Li F, Chen Y, Hong F, Wang H, Chen J (2020) Prognostic factors and clinical outcomes in adult primary gliosarcoma patients: a surveillance, epidemiology, and end results (SEER) analysis from 2004 to 2015. Br J Neurosurg 34:161-167. https://doi.org/10.1080/ 02688697.2019.1699903

28. Ma R, Alexe D-M, Pereira EA (2020) Primary gliosarcoma: epidemiology, clinical presentation, management, and survival. J Neurosurg Sci 64:341-346. https://doi.org/10.23736/S0390-5616.17. 04077-2

29. Walker GV, Gilbert MR, Prabhu SS, Brown PD, McAleer MF (2013) Temozolomide use in adult patients with gliosarcoma: an evolving clinical practice. J Neurooncol 112:83-89. https://doi.org/ 10.1007/s11060-012-1029-7

30. Peckham ME, Osborn AG, Palmer CA, Tsai A, Salzman KL (2019) Gliosarcoma: neuroimaging and immunohistochemical findings. J Neuroimaging 29:126-132. https://doi.org/10.1111/jon.12565

31. Yi X, Cao H, Tang H, Gong G, Hu Z, Liao W et al (2019) Gliosarcoma: a clinical and radiological analysis of 48 cases. Eur Radiol 29:429-438. https://doi.org/10.1007/s00330-018-5398-y

32. Lee D, Kang SY, Suh Y-L, Jeong JY, Lee J-I, Nam D-H (2012) Clinicopathologic and genomic features of gliosarcomas. J Neurooncol 107:643-650. https://doi.org/10.1007/s11060-011-0790-3

33. Rath GK, Sharma DN, Mallick S, Gandhi AK, Joshi NP, Haresh KP et al (2015) Clinical outcome of patients with primary gliosarcoma treated with concomitant and adjuvant temozolomide: a single insti- 
tutional analysis of 27 cases. Indian J Cancer 52:599-603. https:// doi.org/10.4103/0019-509X.178407

34. Adeberg S, Bernhardt D, Harrabi SB, Diehl C, Koelsche C, Rieken $S$ et al (2016) Radiotherapy plus concomitant temozolomide in primary gliosarcoma. J Neurooncol 128:341-348. https:// doi.org/10.1007/s11060-016-2117-x

35. Castelli J, Feuvret L, Haoming QC, Biau J, Jouglar E, Berger A et al (2016) Prognostic and therapeutic factors of gliosarcoma from a multi-institutional series. J Neurooncol 129:85-92. https://doi. org/10.1007/s11060-016-2142-9 